\title{
Poseedor inscrito v/s poseedor material ¿un cambio de paradigma? Comentario a la Sentencia 1376-2017 Civil de la Ilustrísima Corte de Apelaciones de Concepción
}

\section{Registered owner $v / s$ material owner ¿A change of paradigm? Commentary to the Judgment 1376-2017 Civil of the Ilustrious Court of Appeals of Conception}

Daniel alejandro Sánchez Carrasco ${ }^{1}$

\section{RESUMEN}

El presente comentario de jurisprudencia tiene por objeto analizar una sentencia emanada de la ilustrísima Corte de Apelaciones de Concepción, en ella los sentenciadores de dicho tribunal conociendo de un caso en el que se deduce una acción reivindicatoria por parte del dueño no poseedor en contra del poseedor no dueño, deciden no dar lugar a la acción reivindicatoria y fallan a favor del poseedor material del predio, cambiando de esa forma el criterio imperante en nuestra jurisprudencia la que en antańo prefería al poseedor inscrito por sobre el poseedor material.

Palabras claves: Posesión inscrita-posesión material-prescripción adquisitiva.

\section{ABSTRACT}

The purpose of this jurisprudence commentary is to analyze a ruling issued by the illustrious Court of Appeals of Concepción, in it the judgment of said court knowing of a case in which a claiming action is deduced by the non-owner against the non-owner, they decide not to give rise to the claiming action and fail in favor of the property owner of the property, changing in this way the prevailing criteria in our jurisprudence which in the past preferred the registered holder over the material holder.

Keywords: Registered posession - material possession - purchasing prescription.

Licenciado en Ciencias Jurídicas y Sociales por la Universidad Autónoma de Chile. Es profesor par-time de Derecho Civil en la Universidad Autónoma de Chile y diplomado en Filosofía Antigua y Medieval por la Universidad Católica de Temuco. Agradezco la ayuda invaluable que me brindó Karla Abish Dote Arriaga, Alumna de cuarto año de Derecho de la Universidad de Chile, quien contribuyó a la recopilación de doctrina y jurisprudencia para el presente comentario. Correo: das.carrasco@gmail.com 


\section{La cuestión debatida}

Con fecha 28 de octubre del año 2015, se dedujo una acción reivindicatoria por parte de la empresa forestal Mininco S.A., en contra de don Jorge Follador Ernst, sobre el Lote $\mathrm{N}^{\circ} 4$ del «sector Hijuelas», aduciendo que dicho retazo de terreno pertenece al fundo Colliguay, respecto del cual los demandantes declaran ser dueños de él mediante titulo inscrito que data de fecha 20 de noviembre del año 2011. En la fecha recién referida, la demandante adquiere la totalidad de las acciones de la empresa Inmobiliaria y Forestal Maitenes S.A., quien a su vez adquirió el fundo Colliguay mediante el procedimiento contemplado en el Decreto Ley 2695, dictándose la resolución en el año 1999, iniciándose su posesión material en el año 1993. En resumen, haciendo uso de la accesión de posesiones, la demandante dice ser dueña del terreno y que su posesión arranca desde el ańo 1993 mediante un modo de adquirir originario, que en el caso de marras seria la prescripción adquisitiva.

Frente a la demanda deducida por la empresa forestal Mininco S.A., el demandado contesta la demanda, señalando entre sus muchas alegaciones que él cuenta con título inscrito que lo habilita para poseer y ser considerado dueño. Señala que el título que lo habilita para ser considerado poseedor inscrito es más antiguo que el que invoca el demandante, ya que este data desde el año 2014, el cual fue fruto de una reinscripción que se practicó en virtud del Decreto 719 de 15 de julio del año 1998, en resumidas cuentas, el título del demandado data de una fecha más antigua, pues el título que se reinscribió data del año 1992 y a su vez, haciendo uso de la accesión de posesiones, agrega las de sus antecesores, remontándose hasta el ańo 1973. En base a lo seńalado opone la excepción de prescripción extintiva y a su vez demanda reconvencionalmente se declare la prescripción adquisitiva ordinaria del dominio que este ostenta y en subsidio pide que se declare la prescripción adquisitiva extraordinaria.

Dentro de los argumentos de la contestación de la demanda, esta señala que una vez que la demandante adquiere el predio mediante el procedimiento contemplado en el Decreto Ley 2695, esta solo ostentaría una inscripción de papel, por ende, no podría considerársele como poseedora del predio si a la posesión inscrita le falta la posesión material, siéndole inoponible dicha posesión al demandado, el cual ostenta la posesión material.

El tribunal estimó como hecho no controvertido el que ambos poseedores contaban con una inscripción de dominio en el Conservador de Bienes Raíces y que el problema en cuestión surgía de la superposición de predios. Para una acertada resolución del juicio el tribunal razona que quien tiene la posesión inscrita es la demandante, en base al artículo 15 del decreto ley 2695, pues si no se alega el dominio por todos aquellos que ostentan un derecho real sobre la cosa dentro de un año contados desde la dictación de la resolución, no será admisible con posterioridad efectuar alegación alguna, el efecto de la resolución, en virtud del artículo 15 del decreto ley 2695, es la cancelación de pleno derecho de las demás inscripciones y a su vez, si transcurre un año de posesión pacífica, el interesado se hace dueño de la cosa por prescripción adquisitiva.

Lo anterior tuvo como consecuencia que el demandado perdiera la posesión inscrita del predio objeto del juicio, sin embargo, el demandado siguió actuando como dueño del predio, esto es, sin reconocer dominio ajeno.

En base a lo anterior el juez a quo decide desechar la acción reivindicatoria deducida por el demandante y a su vez acoge la acción reconvencional de prescripción extraordinaria. ${ }^{2}$ Fallo que a su vez fue confirmado por la Corte de Apelaciones de Concepción, del cual emana la siguiente doctrina:

Primer Juzgado Civil de Concepción, Rol C-6718-2015. 
"Que, en lo relativo a la alegación de la parte recurrente, en el sentido que no es posible prescribir contra título inscrito, sin título incrito, en conformidad a lo prevenido en el artículo 2505 del Código Civil, esta materia ha sido objeto de discusión doctrinaria y jurisprudencial (sin pacífica conclusión), a la luz del artículo 2510 del Código Civil, que contiene reglas sobre la prescripción extraordinaria, adscribiendo estos sentenciadores a la tesis de la prevalencia de la posesión material por sobre la inscrita, siendo la primera un hecho que consiste en la efectiva tenencia de una cosa con ánimo de dueño, en matiz con la segunda, que se entiende como una mera garantía de posesión. De este modo, la inscripción no es más que una garantía de este hecho posesión, que debe existir en realidad».3

\section{Comentario}

Sin duda la doctrina de la Corte de Apelaciones de Concepción aplica la doctrina correcta, pues como premisa principal señalamos que la inscripción es requisito, garantía y prueba de posesión, sin embargo, para poder optar a los beneficios que nos brinda la inscripción conservatoria, nos es menester que dicha posesión inscrita se condiga con la realidad, no es el fin de la ley el que se proteja una posesión que solo existe en el papel y no en la realidad. Para ello nos es menester recordar lo que señala el mensaje del Código Civil en la materia: «(...) La posesión de los bienes raíces, manifiesta, indisputable, caminando aceleradamente a una época en que inscripción, posesión y propiedad serían términos idénticos $(\ldots)$ ».

Empero, no obstante la finalidad de Andrés Bello respecto al sistema que implementó en nuestro ordenamiento jurídico, la realidad es otra, pues en primer lugar hizo nacer dos tipos distintos de bienes raíces, aquellos que se encuentran inscritos y aquellos que no cuentan con dicha inscripción; además, como lo señala la misma Corte de Apelaciones, podemos señalar que además de la distinción entre dichos tipos de inmuebles, nacieron a su vez dos tipos de posesiones, una posesión material y una posesión inscrita, respecto de la cual el sentenciador no puede obviar al momento de decidir a quién concederle la posesión y el dominio de la cosa.

Lo anterior no es ajeno a lo seńalado por nuestro máximo tribunal, pues de acuerdo al criterio implementado por ella «la posesión es una noción bifronte que supone la concurrencia copulativa de dos clases de posesión (el corpus que vendría a ser la posesión material y el animus la posesión jurídica). Luego, si falta una de ellas, el poseedor inscrito carece de posesión sobre el bien. En estos términos, la posesión es interpretada como una noción integra; así, es la suma de dos elementos o bien de dos especies de posesión». ${ }^{4}$

Por ende, quien desee aprovecharse de los efectos de la inscripción debe ostentar la posesión material de bien, de otra forma se desnaturalizaría el concepto de posesión contenido en el artículo 700 del Código Civil.

En base a lo señalado, haremos un breve análisis del fallo rescatando las discusiones que en antaño se han producido y que nuevamente hoy en día han cobrado vigencia, lo cual estructuraremos de la siguiente forma:

a) Efectos del artículo 15 del Decreto Ley 2695 .

b) Las inscripciones paralelas y la inscripción de papel.

Corte de Apelaciones de Concepción, Rol 1376-2017 Civil.

PEREIRA FREDES (2018) p. 189. 
c) La prescripción contra título inscrito.

Luego, finalizaremos con las conclusiones que nos arroje el análisis del caso.

\section{Efectos del artículo 15 del decreto ley 2695}

El decreto ley 2695 viene a poner en tela de juicio la efectividad del sistema registral implementado por Andrés Bello en nuestro ordenamiento jurídico, pues este comienza en su considerando segundo señalando lo siguiente «Que por ello se ha creado un sistema que la legislación ha denominado "saneamiento de la pequeña propiedad", que tiene por objeto regularizar la situación del poseedor material que carece de títulos (...)». Por ende, el objeto de este decreto ley es regularizar la posesión material de los bienes raíces, es decir, que quien ostente la posesión material puede optar a someterse al procedimiento señalado por este para poder contar con un título e inscribirlo en el Conservador de Bienes Raíces.

Sin embargo, es menester anotar que la existencia de una inscripción anterior no es óbice para el interesado someterse a las disposiciones de este Decreto, pues en el artículo $2^{\circ}$, inciso $2^{\circ}$, del Decreto ley 2695 señala expresamente «No será obstáculo para el ejercicio de este derecho la circunstancia de que existan inscripciones del dominio anteriores sobre el mismo inmueble», lo cual no viene sino a confirmar el problema heredado por el sistema registral de propiedad, pues, no todos los poseedores materiales contaban con la competente inscripción en el Conservador de Bienes Raíces, por ende, resultó necesario dar solución a ese problema mediante la dictación del presente Decreto Ley.

En virtud del procedimiento contenido en el Decreto Ley 2695 el interesado puede obtener un título e inscribirlo en el Conservador de Bienes Raíces, dicho título es una resolución emanada del Ministerios de Bienes Nacionales, el cual una vez dictado y en virtud los artículos 15 y 16 del referido decreto ley, el interesado adquiere la calidad de poseedor regular, sirviendo la resolución del servicio como justo título para poseer, no obstante existan en favor de otras personas inscripciones que no hayan sido previamente canceladas y agrega que transcurrido un año de posesión pacífica de la cosa el interesado se hace dueño de ella por prescripción, quedando de ese modo canceladas todas las inscripciones anteriores de pleno derecho.

Como se aprecia, la norma en comento tiene un poder demoledor en contra del poseedor inscrito, es más, como bien sabemos, para cancelar una inscripción es menester hacer una anotación al margen de la inscripción que se cancela, sin embargo, en este caso solo es exigible aquello cuando se tenía conocimiento de la inscripción anterior.

Pues bien, ¿Qué sucedió en el caso de marras? La demandante adquirió dominio del predio mediante la adquisición de la Forestal Maitenes S.A., la cual a su vez se hizo del dominio de dicho predio mediante el procedimiento contemplado en el decreto ley 2695, lo cual tuvo como gran efecto el hecho de cancelar todas las inscripciones anteriores, por ende, la inscripción que el demandado ostentaba del predio fue cancelada de pleno derecho, aun cuando esta no se haya suscrito al margen del título que se cancela, produciéndose al efecto una verdadera cancelación virtual de las demás inscripciones.

Detentando la posesión inscrita, el demandante pretende recuperar el dominio de la cosa que está en manos del demandado, empero, aquí sucede lo curioso, pues al no contar el primero con la posesión material no puede decirse que se haya cumplido a cabalidad con la finalidad que establece el Decreto Ley 2695, pues, la finalidad de este es otorgar el título a quien no contaba con él y lo que ocurrió en el caso de 
marras es que una vez obtenido el título e inscrito en el Conservador de Bienes Raíces este después no se ocupo del predio. Ello trajo consigo que el demandado siguiera actuando como señor y dueño, pues, al no haberse practicado la subinscripción al margen de la inscripción anterior, trajo como consecuencia que el demandado siguiera actuando como señor y dueńo, no obstante, no contara con una inscripción vigente en el Conservador de Bienes Raíces.

Esto tuvo como resultado la existencia de dos inscripciones y de dos posesiones: una material y otra jurídica, la pregunta es ¿por cual debe optar el juez al momento de fallar el asunto?

\section{Las inscripciones paralelas y las inscripciones de papel}

El caso planteado es el perfecto ejemplo de las inscripciones paralelas, las cuales en palabras del profesor Daniel Peńailillo consisten en «la situación en la cual en el Registro aparecen dos (o más) inscripciones con apariencia de estar vigentes (sin nota de cancelación al margen) o respecto de un mismo inmueble» ${ }^{5}$

Como se puede observar, el caso resuelto por la Corte de Apelaciones de Concepción coincide con lo descrito como inscripciones paralelas, pues en el presente caso existen dos inscripciones sobre un mismo predio o retazo del mismo, en el cual la antigua inscripción no se canceló mediante la subinscripción al margen de esta, sino, que ambos poseedores actuaron como señor y dueño, esto es, sin reconocer dominio ajeno, empero, como hecho probado de la causa, solo el demandado siguió actuando como poseedor material de la cosa, mientras que el demandante se contento con tener la posesión inscrita de la cosa.

Ante tal caso, el juez está obligado a resolver, mas ¿Cómo puede decidir el juez frente a un caso de inscripciones paralelas? Ante tal caso, el juez debe preferir a aquel poseedor que ostente la posesión material, sin embargo, debe tenerse cuidado con el criterio que señalamos, pues debe matizarse según los hechos que obren en la causa, pues, «no parece apropiado considerarlo como el único elemento para decidir; se corre el riesgo de sancionar el predominio de la fuerza» ${ }^{6}$, es decir, si el origen de la posesión material ha sido un acto violento, no puede pensarse que tal situación habilita a una persona para poder poseer y aspirar adquirir la cosa por prescripción adquisitiva, eso sería una posesión violenta, la que en derecho es inútil para poder adquirir el dominio.

En el caso de marras, podemos apreciar que el demandado no hizo uso de la fuerza ni la violencia para estar en posesión material del predio, es más, basa su aprehensión en el título inscrito cancelado virtualmente, lo cual trajo como consecuencia que detentara la cosa sin reconocer dominio ajeno y sin violencia o clandestinidad.

Lo seńalado hasta ahora ha descrito como el juez puede resolver el tema de las inscripciones paralelas, sin embargo, existe otro fundamento que aún no hemos señalado y que es vital para poder entender la razón de la decisión del Juez. Otrora, un Jurista de renombre llamado Leopoldo Urrutia toca el tema de la posesión inscrita, hace un análisis de la misma, matizando los efectos de la inscripción, expresa que no niega los beneficios que la inscripción le otorga al poseedor inscrito, esto es, ser requisito, garantía y prueba de posesión, empero, aquello no puede ir contra lo que realmente ocurre en la realidad, pues, notó que podrían cometerse injusticias o llegar a verdaderos resultados absurdos si se da una prevalencia absoluta a la inscripción. A aquellas inscripciones a las que les falte la posesión material las denominó

Peńailillo Arévalo (2006) p. 281.

Peńailillo Arévalo (2006) p. 282. 
inscripciones de papel señalando para estos efectos: «Para que valga una inscripción contra otra anterior o contra la posesión natural, es necesario que aquella no sea de "papel". La inscripción solemniza un hecho verdadero, y, por lo tanto, no puede solemnizar apoderamientos que no han existido.» ${ }^{7}$

Lo expresado por don Leopoldo Urrutia tiene un sentido lógico innegable, es más, el caso que estamos comentando ocurre exactamente lo descrito por él, pues, compartimos la idea respecto a que los beneficios de la inscripción solo pueden existir si la posesión que se está solemnizando existe en la realidad, en ninguna caso, alguien que ostente una mera inscripción de papel puede aprovecharse de los efectos de ella, aquello conduciría a absurdos en nuestro sistema posesorio. Si lo pensamos detenidamente, el hecho que sirve de base a la inscripción es la posesión material, sin ella malamente podríamos decir que podría llegar a nacer una inscripción en el Conservador de Bienes Raíces, pues «La inscripción es en el fondo solemnidad de un hecho, asegura la posesión; de suerte que, faltando el hecho de la posesión, nada solemniza ni asegura» ${ }^{8}$

En resumidas cuentas, la inscripción vendría a ser el envase de la posesión material, sin ella, esta vendría a ser un cascaron vacío. Lo señalado viene a plantearnos otro dilema, pues, ¿en qué situación se encontraría el poseedor inscrito que solo detenta una inscripción de papel? El tema no es baladí, para responder aquello me serviré de las palabras del profesor Víctor Vial quien nos ilustra "para que opere la prescripción no basta que se tenga la posesión d la cosa, sino que es imprescindible, además, el ejercicio de actos posesorios, pues son estos los que permiten enterarse de la posesión a la persona que tiene derecho a oponerse a ella. Así, la posesión que solamente se funda en la inscripción y que no va aparejada de la ejecución de actos posesorios es inútil»?

Lo señalado por el profesor Víctor Vial resulta trascendental, en el sentido de que agrega a lo referido por don Leopoldo Urrutia el hecho de que la inscripción de papel constituye un caso de posesión inútil, por ende, no habilita al poseedor para adquirir la cosa por prescripción adquisitiva, sea ordinaria o extraordinaria.

Como vemos, el fallo emanado de la Corte de Apelaciones de Concepción calza de una manera perfecta con la doctrina a que hemos hecho referencia, pues existiendo inscripciones paralelas, el juez da por probada la cancelación virtual de la inscripción del demandado, empero, a este último le da la calidad de poseedor material, la cual nace del hecho lícito de la convicción de este de ser dueño de la cosa, pues este no se entera de la cancelación de la inscripción, debido a que esta no se anota al margen de su inscripción. Luego, el juez desecha la acción reivindicatoria, pues la posesión inscrita del demandante se funda en una mera inscripción de papel, la cual no habilita al poseedor inscrito a adquirir la cosa por prescripción adquisitiva (por ser una posesión inútil), prefiriendo en este caso al poseedor material, declarando a su favor la prescripción adquisitiva extraordinaria que este solicita se declare en su demanda reconvencional.

Empero, como notamos, nos queda un punto por dilucidar en el presente caso, pues anotamos al final del párrafo anterior que el juez declara la prescripción adquisitiva extraordinaria en favor del demandado, pero ¿Cómo pudo el juez haber fallado de tal forma sin infringir el artículo 2505 del Código Civil? A esto nos referiremos en el siguiente acápite.

\footnotetext{
Urrutia Anguita . Revista de Derecho y Jurisprudencia, Tomo 31, números 1 y 2, p.11.

Urrutia Anguita,(2006) p.12.

Vial del Rio (2009) pp.189-190.
} 


\section{La prescripción contra titulo inscrito}

Para completar nuestro comentario, nos es menester rescatar una vieja querella doctrinaria, referente a si es posible prescribir contra título inscrito. En el caso de marras podemos ver que el juez a quo y ad quem fallaron a favor del demandado, permitiendo la prescripción contra título inscrito, existiendo una prevalencia de la posesión material por sobre la inscrita. Sin embargo, debemos desentrańar el fundamento subyacente en la decisión de la Corte de Apelaciones, para lo cual, nos basaremos en la teoría que apunta a que es posible prescribir contra título inscrito, pues fue esta la usada por aquellos para fallar el caso, esta teoría señala lo siguiente: «Don Ruperto Bahamonde, seguido por don Juan Esteban Montero, afirma que el artículo 2505 se refiere solo a la prescripción ordinaria; en consecuencia, un inmueble inscrito se puede adquirir por prescripción extraordinaria sin necesidad título inscrito. En conformidad a esta doctrina, el individuo que se apodera materialmente de un inmueble inscrito, y lo posee durante diez años sin violencia, clandestinidad ni interrupción, se hace dueño de él, por la prescripción extraordinaria (...) Agregase que de no aceptarse esta doctrina jamás habría prescripción extraordinaria contra título inscrito y se llegaría al absurdo de que la ley protege al propietario negligente, en perjuicio del que trabaja el inmueble.» ${ }^{10}$

Lo recién señalado, como es sabido, no ha sido la doctrina mayoritaria ni la que ha tenido mejor acogida en nuestra jurisprudencia, empero, en otras ocasiones se ha recogido este argumento por nuestros tribunales superiores de justicia. En una ocasión la Corte de Apelaciones de Santiago nos ilustró con la siguiente doctrina: «Establecido que el demandado ha estado en posesión material del inmueble que se trata de reivindicar, no procede sostener que es improcedente la prescripción alegada por aquel por estar vigente la inscripción hecha al demandante y por impedirlo el artículo 2505 del Código Civil y las demás disposiciones relativas a la posesión inscrita, pues en este caso no se trata de la adquisición o perdida de la posesión, sino la del dominio, para cuya adquisición o perdida no exige la ley la posesión jurídica, sino la material, por lo que es inoficioso ocuparse de las disposiciones legales referentes a esa posesión.» ${ }^{11}$

Relacionado con lo seńalado anterior, también la Corte Suprema una vez se mostró favorable en aplicar la doctrina en comento, señalando lo siguiente: «Exigir la cancelación de la inscripción anterior por alguno de los medios señalados en el artículo 728 del Código Civil como requisito indispensable para que pueda iniciarse la posesión inscrita del prescribiente de prescripción extraordinaria, equivale a exigir como como elemento necesario de dicha prescripción la existencia de un título y para esa clase de prescripción no hace falta título alguno... La prescripción es a la vez titulo y modo de adquirir, de manera que no es necesaria la tradición, y la mención que a este modo de adquirir se hace en el artículo 724 del Código Civil solo tiene el valer de una referencia respecto de los bienes en que la posesión no se adquiera sino mediante la inscripción.» ${ }^{12}$

Con lo citado, podemos deducir que la sentencia emanada de la Corte de Apelaciones de Concepción es ajustada a la doctrina en comento, tanto la doctrina y los fallos citados, dan a entender que al estar frente a un caso de prescripción extraordinaria no es aplicable el artículo 2505, dado a que la prescripción extraordinaria no exige titulo alguno para que esta opere. Sin embargo, esta doctrina debe matizarse, pues, según nosotros, esta doctrina solo será aplicable si quien tiene la posesión inscrita detenta una mera inscripción de papel, en otros casos, no podría aplicarse el 2510, pues al poseedor inscrito lo ampararían todos los beneficios que conlleva la inscripción, es más, tampoco podría aplicarse el 2510 si el hecho que

\footnotetext{
Alessandri; Somarriva; Vodanovic (1971) p.583.

Revista de Derecho y Jurisprudencia, Tomo 36, Segunda parte, Sección segunda, p.2.

Revista de Derecho y Jurisprudencia, tomo 41, Segunda parte, Sección primera, p.275.
} 
da origen a la posesión material es violento o si la posesión se ejerce con clandestinidad, en ambos casos la posesión sería inútil, haciendo imposible la aplicación del 2510.

Entonces, ¿Cuándo el poseedor material puede prescribir contra título inscrito? Si aceptamos la posibilidad de que el artículo 2505 no es aplicable al caso de la prescripción extraordinaria, debemos señalar que como primer requisito que debe cumplirse para que el poseedor material pueda prescribir contra título inscrito es que quien detenta la posesión inscrita debe contar con una inscripción de papel; en segundo lugar, quien aspire a adquirir la cosa mediante la prescripción adquisitiva extraordinaria debe detentar a lo menos la posesión material de la cosa; en tercer lugar, debe existir una justa causa que motive al poseedor material a actuar como señor y dueño de la cosa.

Es en este último requisito en donde quiero detenerme, pues, como podrán apreciar, tanto en el caso de marras y en los fallos citados, siempre existió una justa causa que permitió que aquel poseedor material actuara como señor y dueño de la cosa, pues, en el caso que comentamos el demandado actúa como tal porque estima que su inscripción es válida, no hace una mera apropiación material, ni es violenta ni clandestina, lo cual, lo faculta para tener una convicción de ser el legitimo dueño de la cosa, teniendo de esa forma el corpus y el animus exigido en el artículo 700 del Código Civil.

Agreguemos lo siguiente, que además de tener esta justa causa que me habilita a ser poseedor material, señalemos que las inscripciones de papel son inútiles para adquirir la cosa por prescripción adquisitiva, entonces cabe hacernos las siguiente pregunta: ¿Quién es el dueño de la cosa cuando existe una mera inscripción de papel? Resulta interesante esta pregunta, pues en base al análisis hecho a lo largo de este comentario, nos parece forzoso concluir que será dueño de la cosa aquel que en definitiva ostente la posesión material de la cosa, siempre y cuando ella arranque de un hecho que constituya una justa causa de posesión.

\section{Conclusión}

Para concluir nuestro comentario, expresamos que lo señalado deja entre ver las falencias del sistema registral en nuestro ordenamiento jurídico, ante ello, la jurisprudencia tuvo que conceptualizar dos especies distintas de posesión: una es la posesión material y la otra es la posesión jurídica. A raíz de aquello, concluimos fehacientemente que la inscripción en el conservador de bienes raíces es requisito, garantía y prueba de posesión, empero, aquel beneficio solo puede ser alegado por el poseedor inscrito que cuente con la posesión material del inmueble, pues, la inscripción no viene sino a solemnizar el hecho de la posesión material, en caso contrario, la inscripción sería de papel, la cual es una posesión inútil que inhabilita a aquel poseedor a adquirir la cosa por prescripción adquisitiva.

Actualmente la confrontación de la posesión material e inscrita no es baladí, es más, atendido a los problemas que esta ha generado, el legislador se vio forzado a regularizar dicha situación con la dictación del decreto ley 2695, el cual tiene por finalidad regularizar la propiedad del poseedor material, la que una vez cumplidos los tramites señalados en él este puede adquirir la cosa mediante la prescripción adquisitiva. Con ello confirmamos la noción bifronte que existe en materia posesoria.

Lo anterior trae como consecuencia que pueda darse el caso de inscripciones paralelas, ya que, si se adquiere la cosa mediante el procedimiento consagrado en el decreto ley 2695, no es menester 
subinscribir al margen de la inscripción la cancelación de esta, siendo esta una cancelación virtual, esto conlleva a que el sentenciador en un caso de esa características deba preferir por aquel que ostente la posesión material de la cosa.

Sin embargo, siempre debe tenerse cuidado en este punto, pues, para que el poseedor material pueda aspirar a adquirir la cosa mediante la prescripción adquisitiva es menester que este dispute el dominio de la cosa con un poseedor inscrito que solo cuente con una inscripción de papel, a su vez él debe tener la posesión material y lo mas importante es que exista una justa causa que lo habilite a comportarse como poseedor material del inmueble, de esa forma el puede adquirir la cosa mediante la prescripción adquisitiva extraordinaria, pues, el artículo 2505 solo es aplicable a la prescripción adquisitiva ordinaria, arribar a una conclusión diversa echaría por tierra la teoría de las inscripciones de papel si no se permitiera que el poseedor material pueda adquirir la cosa por prescripción adquisitiva extraordinaria frente a aquel que detenta una mera inscripción de papel.

Para concluir, dejo la reflexión referente a que estos problemas se suscitan siempre que el legislador mediante el texto legal busca desnaturalizar la realidad, en el sentido de hacer una afirmación de que A es A cuando la proposición en la realidad puede ser A es B, aquello genera un choque entre la literalidad de la norma (deber ser) con la realidad empírica que esta misma pretende regular (el ser), ambas generan el problema en el sentenciador, sobre si debe preferir la aplicación de la norma por sobre los hechos que han sido probados en juicio, ello trae como consecuencia que en nuestra jurisprudencia el juez busque formas para hacer calzar ambas nociones, lo cual, como hemos venido señalando en nuestro análisis ha intentado hacer el juez, aplicando desde nuestro punto de vista la correcta doctrina, que es que aquel que en la realidad objetiva detenta la cosa como poseedor natural, teniendo una justa causa para actuar como tal debe ser preferido por aquel que solamente ostenta una mera inscripción de papel.

\section{Bibliografía citada}

\section{Libros}

Alessandri, A; Somarriva, M; Vodanovic, A. (1971) Curse de Derecho Civil: Los Bienes y los Derechos Reales. Editorial Nascimento, tercera edición, Santiago de Chile.

Peñailillo Arévalo, D. (2006) Los Bienes, La Propiedad y otros Derechos Reales. Editorial Jurídica de Chile, Santiago de Chile.

Vial del Rio, V. (2009) La Tradición y la Prescripción como Modos de Adquirir el Dominio. Ediciones Universidad Católica de Chile, Santiago, Chile.

\section{Revistas}

Pereira Fredes, E. (2018). Desprotección como Paradoja de la Inscripción: Cuestiones de Justificación de la Teoría de la Posesión Inscrita, Estudios de Derecho Civil XIII, Editorial Thomson Reuters.

Urrutia Anguita, L., Vulgarización Sobre la Posesión ante el Código Civil Chileno, Revista de Derecho y Jurisprudencia, Tomo 31, números 1 y 2.

Revista de Derecho y Jurisprudencia, Tomo 36, Segunda Parte, Sección Segunda.

Revista de Derecho y Jurisprudencia, tomo 41, Segunda Parte, Sección Primera. 


\section{Jurisprudencia citada}

Forestal Mininco S.A., con Follador Ernst (2017), Primer Juzgado Civil de Concepción, 30 de Junio de 2017, rol C-6718-2015, dictada por Margarita Sanhueza Núńez.

Forestal Mininco S.A., con Follador, Ernst (2018), Ilustrísima Corte de Apelaciones de Concepción, 10 de Julio de 2018, rol 1376-2017, redacción Mauricio Ortiz Solorza (abogado integrante). 